\title{
Current situation and trends of online academic activities for oncologists during the COVID-19 pandemic: a multicenter survey
}

\author{
Fei Gao ${ }^{1 \#}$, Luopei Wei" ${ }^{2 \#}$,ichen Chen ${ }^{3 \#}$, Wen Shang ${ }^{4}$, Zhuoyu Yang ${ }^{5}$, Yan Wen ${ }^{5}$, Shida Yan ${ }^{3}$, Hanjie Hu ${ }^{3}$, \\ Rui Zhang ${ }^{6}$, Ni $\mathrm{Li}^{5}$, Hong Zhao ${ }^{3}$
}

${ }^{1}$ Publicity Department, National Cancer Center/National Clinical Research Center for Cancer/Cancer Hospital, Chinese Academy of Medical Sciences and Peking Union Medical College, Beijing, China; ${ }^{2}$ Department of Science and Development, The Second Affiliated Hospital of Zhejiang University School of Medicine, Hangzhou, China; ${ }^{3}$ Department of Hepatobiliary Surgery, National Cancer Center/National Clinical Research Center for Cancer/Cancer Hospital, Chinese Academy of Medical Sciences and Peking Union Medical College, Beijing, China; ${ }^{4}$ Department of Radiotherapy, Cancer Hospital of China Medical University, Liaoning Cancer Hospital \& Institute, Shenyang, China; ${ }^{5}$ Office of Cancer Screening, National Cancer Center/National Clinical Research Center for Cancer/Cancer Hospital, Chinese Academy of Medical Sciences and Peking Union Medical College, Beijing, China; ${ }^{6}$ Department of Colorectal Surgery, Cancer Hospital of China Medical University, Liaoning Cancer Hospital \& Institute, Shenyang, China

Contributions: (I) Conception and design: R Zhang, N Li, H Zhao; (II) Administrative support: R Zhang, N Li, H Zhao; (III) Provision of study materials or patients: F Gao, L Wei, Q Chen; (IV) Collection and assembly of data: All authors; (V) Data analysis and interpretation: F Gao, L Wei, Q Chen; (VI) Manuscript writing: All authors; (VII) Final approval of manuscript: All authors.

\#These authors contributed equally to this work.

Correspondence to: Rui Zhang. Department of Colorectal Surgery, Cancer Hospital of China Medical University, Liaoning Cancer Hospital \& Institute, Shenyang, China. Email: zhangrui@cancerhosp-ln-cmu.com; Ni Li. Office of Cancer Screening, National Cancer Center/National Clinical Research Center for Cancer/Cancer Hospital, Chinese Academy of Medical Sciences and Peking Union Medical College, Beijing, China. Email: nli@cicams.ac.cn; Hong Zhao. Department of Hepatobiliary Surgery, National Cancer Center/National Clinical Research Center for Cancer/ Cancer Hospital, Chinese Academy of Medical Sciences and Peking Union Medical College, Beijing, China. Email: zhaohong@cicams.ac.cn.

Background: The present study aimed to investigate the current situation and future trends of online academic activities for oncologists during the coronavirus disease 2019 (COVID-19) pandemic.

Methods: From April 22 to May 5, 2020, a multicenter survey was conducted using an online questionnaire platform. To compare categorical variables, $\chi^{2}$-test, the kappa consistency analysis, and Wilcoxon rank sum test were applied. For all statistical hypotheses, $\mathrm{P}<0.05$ was considered significant.

Results: In the present study, 2,120 oncologists participated in the survey. Of these, 2,035 respondents participated in online academic activities. During the pandemic, online academic activities significantly increased [oncologists who participated in online academic activities $\geq 60 \%: 64.58 \%$ (during the pandemic) vs. $10.90 \%$ (before the pandemic), Cohen's kappa coefficient $=0.0499, \mathrm{P}<0.001]$. The findings indicated that $90.6 \%$ of respondents considered that the online academic activities would become a future trend. The main reason for the increase in online academic activities was due to in-person academic conferences and diagnoses/treatment being affected by the pandemic. Both speakers/chairs and audiences agreed that online academic activities resulted in reduced stress $\left(61.15 \%\right.$ vs. $67.26 \%$, respectively; $\left.\chi^{2}=7.009, \mathrm{P}=0.03\right)$. In the present study, $62.21 \%$ of audiences considered that the recording function of online activities was very important (score 5), while only $53.86 \%$ of the speakers had the same opinion $(Z=-3.5340, P<0.001)$. Compared with provincial capital cities and other cities, the participants from first-tier cities thought that online academic activities required significant physical energy $\left(\chi^{2}=6.41, \mathrm{P}=0.040\right)$, and were more reluctant for the playback of activity contents $\left(\chi^{2}=9.33, \mathrm{P}=0.002\right)$ and the screenshot of activity contents $\left(\chi^{2}=41.99\right.$, $\mathrm{P}<0.001)$.

Conclusions: During the COVID-19 pandemic, online academic activities have become the main form of academic exchanges for oncologists. Taking full advantage of online academic activities and paying adequate attention to the participants' requirements with different roles and titles, and from different cities, are key to 
improving the quality of and involvement in online academic activities.

Keywords: Coronavirus disease 2019 (COVID-19); online academic activities; oncology; multicenter survey

Submitted Jun 30, 2020. Accepted for publication Oct 23, 2020.

doi: $10.21037 /$ atm-20-5051

View this article at: http://dx.doi.org/10.21037/atm-20-5051

\section{Introduction}

Since the first reported outbreak in December 2019, coronavirus disease 2019 (COVID-19) has become a global pandemic (1). Since June 13, 2020, COVID-19 has spread to over 214 countries with over 7,553,182 confirmed cases, posing a major public health challenge worldwide (2). Global governments have imposed strict travel restrictions and social distancing rules to flatten the curve of the contagion (3).

To reduce gatherings and avoid cross-infection, the number of offline domestic and international academic activities has significantly decreased, which has had a significant impact on academic exchanges and oncology diagnosis and treatment. Based on this, online academic activities have become an accessible and cost-effective alternative to traditional offline academic activities (4), and this platform has become a new model of academic exchange for oncologists. On March 17, Nature published an online article on 2020 being a year without in-person academic activities (5). The pandemic has encouraged researchers to share academic findings and exchanges online, highlighting online academic activities' importance. In the present multicenter survey study, we investigated online academic activities and analyzed the differences in participants with different roles and titles, and from different cities, to improve these specialists' quality and involvement in online academic activities.

We present the following article in accordance with the Quality assessment criteria for survey research reports Checklist (available at http://dx.doi.org/10.21037/atm-205051).

\section{Methods}

\section{Respondents}

Oncologists currently working in hospitals from national medical centers were invited to participate in our study from April 22 to May 5, 2020 via an online questionnaire platform called Oncologynews (a large, comprehensive medical media platform). The present study's inclusion criterion was oncologists currently working in hospitals; the exclusion criterion was questionnaires with incomplete information. All respondents understood and agreed that their answers to the questionnaires would be used for the analyses and reports. The study was conducted in accordance with the Declaration of Helsinki (as revised in 2013). No other personal information was collected in the questionnaire. All participants in this survey have individual consent. The Research Ethics Committee of Cancer Hospital, Chinese Academy of Medical Sciences indicated that no ethics approval was required.

The participants were divided into the following groups, based on their roles: speakers, chairmen, audiences, and organizers. The groups were divided into first-tier cities, provincial capital cities, and other cities in China, based on the participants' locations. First-tier cities were defined as metropolises. In the present study, first-tier cities were Beijing, Shanghai, Guangzhou, and Shenzhen. The participants were divided into chief physician/ associate chief physician, attending physician, and resident physician/student physician, based on their job titles. Student physicians were defined as postgraduate medical students, majoring in oncology. The behavioral patterns and evaluation of the online academic activities were respectively analyzed between different subgroups.

\section{Questionnaire design and implementation}

The electronic questionnaire was designed by Delphi method. The questionnaire contained the following parts: (I) basic information, including the city, hospital, department, professional title, and role; (II) frequency of participation in online academic activities before and during the pandemic; (III) investigation of advantages and disadvantages of online academic activities; (IV) analysis of online academic activities, including the style, frequency, time interval, and duration of each activity; and (V) evaluation of the energy consumption, stress, and functional requirements associated with online academic activities. For some questionnaire 
Table 1 Characteristic of respondents

\begin{tabular}{|c|c|}
\hline Items & $\begin{array}{l}\text { Respondents } \\
(\mathrm{n}=2,120), \mathrm{n}(\%)\end{array}$ \\
\hline \multicolumn{2}{|l|}{ City } \\
\hline First-tier cities & $185(8.73)$ \\
\hline Provincial capital cities & $534(25.19)$ \\
\hline Other & $1,401(66.08)$ \\
\hline \multicolumn{2}{|l|}{ Hospital category } \\
\hline Special oncology hospitals & $241(11.37)$ \\
\hline Grade III level A hospitals & $1,189(56.08)$ \\
\hline Other hospitals & $690(32.55)$ \\
\hline \multicolumn{2}{|l|}{ Department } \\
\hline Medical oncology & $1,480(69.81)$ \\
\hline Oncology surgery & $243(11.46)$ \\
\hline Radiation oncology & $203(9.58)$ \\
\hline Other & $194(9.15)$ \\
\hline \multicolumn{2}{|l|}{ Job title } \\
\hline Chief physician/associate chief physician & 789 (37.22) \\
\hline Attending physician & $946(44.62)$ \\
\hline Resident physician/student physician & $385(18.16)$ \\
\hline \multicolumn{2}{|l|}{ Participation in online academic activities } \\
\hline No & $85(4.01)$ \\
\hline Yes & 2,035 (95.99) \\
\hline \multicolumn{2}{|l|}{ Status ${ }^{\star}$} \\
\hline Speakers & $438(21.52)$ \\
\hline Chairmen & $15(0.74)$ \\
\hline Audiences & $1,564(76.86)$ \\
\hline Organizers & $18(0.88)$ \\
\hline
\end{tabular}

*, only 2,035 people involved in online activities during the pandemic.

entries (style of academic activities, time interval, and academic activities sponsor), respondents could provide multiple responses. For other questionnaire entries, respondents could only provide one response.

According to the Kendan sample size estimation method, the sample size was 10 times that of the number of questionnaire entries. Taking into account the effectiveness of the sample, the sample size increased by a further $15 \%$. There was a total of 19 questionnaire entries in the present study. The minimum sample size of this study was $219[19 \times 10 \times(1+15 \%)]$. Convenience sampling was used to reduce sample bias. A total of 2,120 participants were included, and the sample size was large enough. The electronic questionnaire was designed in advance, and was uploaded onto the Oncologynews questionnaire platform. We sent the questionnaire to participants through the Oncologynews WeChat platform, and the respondents completed the questionnaire using this. After completion of the survey, data were collected directly through the questionnaire platform.

\section{Statistical analysis}

Statistical analyses were performed by the SAS 9.4 software. Qualitative data were described as frequencies and percentages. $\chi^{2}$-test was applied to compare categorical variables. Kappa consistency analysis was used to detect changes in online academic activities before and during the pandemic. Participants rated the software's functional requirements on a $1-5$-point range, with 5 points indicating that it was very important; these were compared between groups using Wilcoxon rank sum test. $\mathrm{P}<0.05$ was considered significant.

\section{Results}

\section{Basic information}

The total number of the respondents in the study was 2,120 (response rate: $100 \%$ ). Of these, 2,035 respondents responded that they participated in online academic activities. The present study aimed to investigate the current situation of oncologists who participated in online academic activities. Therefore, the 85 participants who did not participate in online academic activities were considered invalid, and these respondents were not included in the subgroup analysis. The effective response rate was $95.99 \%$ $(2,035 / 2,120)$.

Among the respondents, $69.81 \%$ were oncology medicine clinicians. All oncologists were chief physicians/ associate chief physicians (37.22\%), attending physicians (44.62\%), or resident physicians/student physicians (18.16\%). A total of 241 respondents (11.37\%) were from specialist oncology hospitals; 1,189 respondents (56.08\%) were from grade III, level A hospitals; and 690 respondents $(32.55 \%)$ were from other hospitals. Also, the 2,035 respondents who participated in online academic activities included 438 speakers, 15 chairs, 1,564 audiences, and 18 organizers (Table 1). 
Table 2 Changes in the online academic activities before and during the pandemic

\begin{tabular}{|c|c|c|c|c|c|c|c|c|}
\hline $\begin{array}{l}\text { During the COVID-19 } \\
\text { pandemic }\end{array}$ & \multicolumn{5}{|c|}{ Before the COVID-19 pandemic } & Total & $\begin{array}{c}\text { Cohen's Kappa } \\
\text { coefficient }\end{array}$ & $P$ \\
\hline Never attend & 24 & 38 & 11 & 5 & 7 & 85 & 0.0499 & $<0.001$ \\
\hline Less than $20 \%$ & 8 & 69 & 21 & 5 & 8 & 111 & & \\
\hline $20-40 \%$ & 5 & 95 & 56 & 7 & 8 & 171 & & \\
\hline More than $60 \%$ & 97 & 789 & 235 & 65 & 183 & 1,369 & & \\
\hline Total & 148 & 1,212 & 414 & 115 & 231 & 2,120 & & \\
\hline
\end{tabular}

\section{Changes in online academic activities before and during the pandemic}

During the pandemic, the number of online academic activities significantly increased [oncologists who participated in online academic activities $\geq 60 \%$ : $64.58 \%$ (during the pandemic) vs. 10.90\% (before the pandemic); $40-60 \%$ : $18.11 \%$ (during the pandemic) vs. $5.42 \%$ (before the pandemic), Cohen's kappa coefficient $=0.0499$, $\mathrm{P}<0.001]$ (Table 2). The main reason for increased online academic activities was in-person academic conferences and diagnoses/treatment being affected by the pandemic (Figure 1A). Analysis of the advantages and disadvantages of online academic activities indicated that reduction of cost and physical activities, flexibility of time, and convenience in attending conferences were the main advantages of online academic activities (Figure 1B). At the same time, lack of post-meeting communication and high demand for access to the internet were the main disadvantages (Figure 1C).

\section{Differences between speakers/chairs and audiences in online academic activities}

During the pandemic, a total of 2,035 respondents stated that they had participated in online academic activities ( 438 speakers, 15 chairmen, 1,564 audiences, and 18 organizers). Because chairs are also speakers, they were allocated to the speakers/chairmen group for the subgroup analysis. The number of organizers was only 18 and they could not be classified as speakers or audiences, so they were not included in the subgroup analysis. Compared to audiences, the frequency of speakers/chairmen who participated in online academic activities was significantly highest in the "1-3 times a week" option $\left(\chi^{2}=4.26, \mathrm{P}=0.038\right)$ (Table 3).
Both speakers/chairs and audiences agreed that online academic activities resulted in reduced stress $(61.15 \% \mathrm{vs}$. $67.26 \%$, respectively; $\chi^{2}=7.009, \mathrm{P}=0.03$ ). A total of $91.88 \%$ of audiences and $86.09 \%$ of speakers/chairs thought that online academic activities would become a future trend $\left(\chi^{2}=13.78, \mathrm{P}<0.001\right)$. Participants rated the software's functional requirements on a 1-5-point range, with 5 points indicating that it was very important. A total of $62.21 \%$ of audiences considered that the recording function of online activities was very important (score 5), while only 53.86\% of speakers/chairs had the same opinion (Wilcoxon rank sum test, $Z=-3.5340, \mathrm{P}<0.001)$. There was no significant difference between speakers/chairs and audiences in the function requirements of high-speed internet access, screen sharing, and esthetic features (Table 4).

\section{Differences between participants from different cities in online academic activities}

Compared with respondents from provincial capital cities and other cities, the proportion of respondents from firsttier cities who participated in online academic activities on working days was higher $\left(\chi^{2}=38.70, \mathrm{P}<0.001\right)$. In firsttier cities, the frequency of participants who participated in online academic activities was significantly higher in the "1-3 times a week" option $\left(\chi^{2}=13.62, \mathrm{P}<0.001\right)$ (Table 5). Compared with provincial capital cities and other cities, participants from first-tier cities considered that online academic activities required significant physical energy $\left(\chi^{2}=6.41, P=0.040\right)$, and they were more reluctant for the playback of activity contents $\left(\chi^{2}=9.33, \mathrm{P}=0.002\right)$ and the screenshot of activity contents $\left(\chi^{2}=41.99, \mathrm{P}<0.001\right)$ (Table 6). 

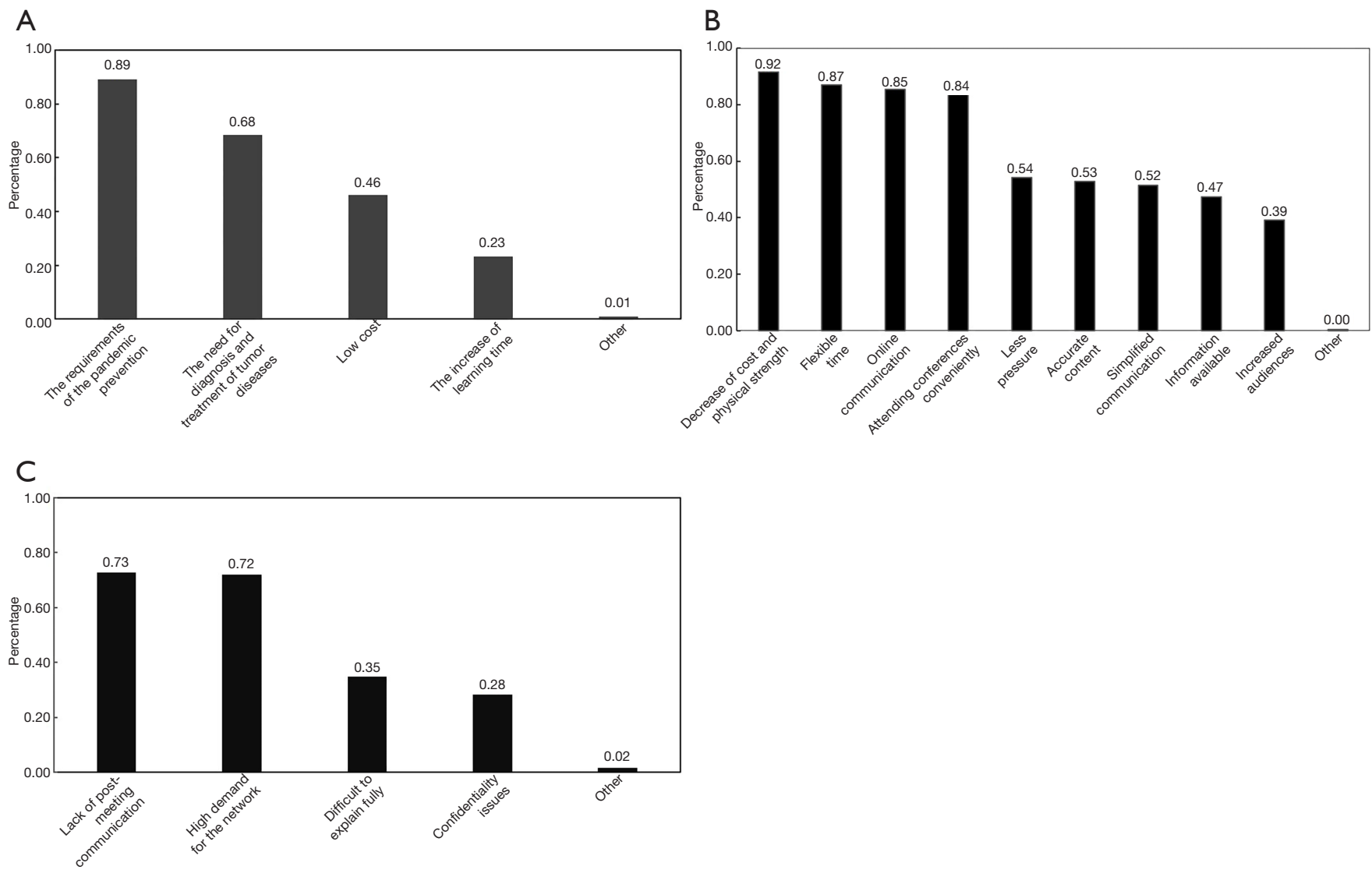

Figure 1 Survey of characteristics of online academic activities during the pandemic. (A) Reasons for increase in online academic activities during the pandemic; (B) advantages of online academic activities; (C) disadvantages of online academic activities.

\section{Differences between participants with different professional titles in online academic activities}

The proportion of resident physicians/student physicians who participated in online academic activities on working days was higher $\left(\chi^{2}=7.17, \mathrm{P}=0.027\right)$ than the physician/ associate chief physicians and attending physicians. Resident physicians/student physicians who participated in online academic activities was significantly higher in the " $1-3$ times a week" option $\left(\chi^{2}=4.55, \mathrm{P}=0.032\right)$ (Table 7). Compared with the physician/associate chief physicians and attending physicians, the frequency of student physicians who participated in online academic activities was significantly higher in the " $1-3$ times a week" option $\left(\chi^{2}=4.26, \mathrm{P}=0.038\right)$.

\section{Discussion}

The results of the survey, which was completed by 2,120 oncologists from all over China, revealed that online academic activities have become the main form of academic exchanges during the COVID-19 pandemic, and the proportion of online academic activities has increased significantly compared to before the pandemic, which is consistent with another online survey results (6). Oncologists from grade III, level A hospitals, from the medical oncology department, with a job title of chief physician or associate chief physician, and as speakers/ chairmen, were more likely to participate in online academic activities (change $\geq 40 \%$ ) during the pandemic (Table S1). Also, Reasons for the significant increase in online academic activities are varied. First, the outbreak of the COVID-19 pandemic led to strict government restrictions, which resulted in a significant increase in online academic activities; second, academic exchanges and sharing of research findings have increased in the frequency of online academic activities, particularly in the context of the diagnosis and treatment of cancer patients during the pandemic. 
Table 3 Differences of situation in the online academic activities between speakers/chairmen and audiences

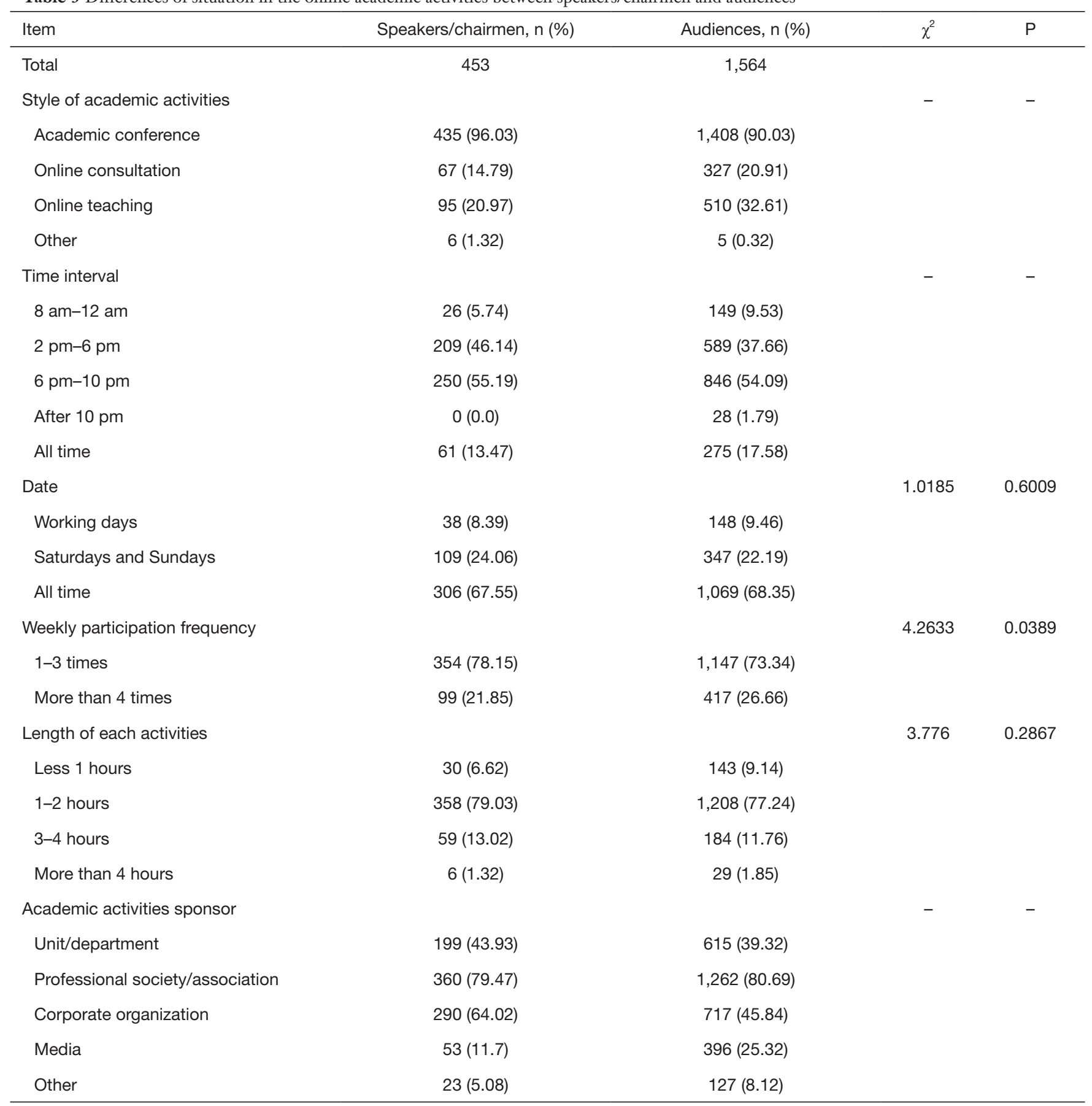

During the pandemic, online academic activities have provided oncologists a platform to diversify academic exchanges, continuing education, and telemedicine. The Chinese Anti-cancer Association encouraged various branches to carry out various online academic activities, such as work meetings, seminars, training courses, and public popular science activities, to build a diversified platform for oncologists in different professions. On April 13, 2020, more than 30 oncology hospitals and a total of more than 1,000 oncologists participated in the large-scale 
Table 4 Evaluation of the online academic activities between speakers/chairmen and audiences

\begin{tabular}{|c|c|c|c|c|}
\hline Item & Speakers/chairmen, n (\%) & Audiences, n (\%) & $\chi^{2} / Z$ & $P$ \\
\hline Energy consumption & & & $\chi^{2}=4.3942$ & 0.1111 \\
\hline Decrease & 332 (73.29) & $1,217(77.81)$ & & \\
\hline No change & $81(17.88)$ & $242(15.47)$ & & \\
\hline Pressure & & & $\chi^{2}=7.0095$ & 0.0301 \\
\hline Decrease & 277 (61.15) & $1,052(67.26)$ & & \\
\hline No change & $143(31.57)$ & 397 (25.38) & & \\
\hline Increase & $33(7.28)$ & 115 (7.35) & & \\
\hline Willing & $453(100.00)$ & $1,553(99.30)$ & & \\
\hline Future prevalence judgment & & & $\chi^{2}=13.7801$ & 0.0002 \\
\hline No & 63 (13.91) & $127(8.12)$ & & \\
\hline Yes & 390 (86.09) & 1,437 (91.88) & & \\
\hline \multicolumn{5}{|c|}{ The software function requirements of online academic activities for different status* } \\
\hline Internet access & $363(80.13)$ & $1,272(81.33)$ & $Z=-0.7277$ & 0.4668 \\
\hline Recording function & $244(53.86)$ & $973(62.21)$ & $Z=-3.5340$ & 0.0004 \\
\hline Screen sharing & $294(64.9)$ & $1,050(67.14)$ & $Z=-1.0312$ & 0.3024 \\
\hline
\end{tabular}

*, the table showed the number and percentage of respondents with a score of 5 , and Wilcoxon rank-sum test was used to compared between groups.

online Q\&A session to guide the diagnosis and treatment of tumors during the pandemic (7). Online academic activities have provided a platform for clinicians in various countries to exchange anti-pandemic experiences, management measures for cancer patients, and the latest anti-pandemic research findings. On April 1, 2020, an international online forum attracted experts and scholars from countries, such as China, France, Spain, and Brazil to share their experiences on how to work together to cope with the COVID-19 pandemic and how to adjust the diagnostic and treatment strategies of cancer patients (8).

Compared with traditional in-person academic activities, online academic activities have unique advantages. First, traditional academic activities require in-person attendance at a particular location. This interferes with clinicians' work schedules and requires travel, which takes time and involves costs for flights and accommodation. Some clinicians, especially young clinicians, may not attend in-person activities due to lack of funds or visas. Online academic activities have the advantages of low cost, flexibility of time, and convenience in participation. These advantages effectively solve the problems mentioned above of traditional in-person academic activities and were particularly highlighted in the respondents' present study. Second, during traditional academic activities, some audiences may not be able to see or hear the speakers when in a big lecture hall; audiences usually only have 1 opportunity for communication and discussion, which is not conducive to repeated learning after the meeting. Online academic activities allow audiences to meet with speakers face-to-face, which makes audiences feel closer to speakers, while the recording function of online academic 
Table 5 Differences of situation in the online academic activities between participants from different cities

\begin{tabular}{|c|c|c|c|c|c|}
\hline Item & First-tier cities, n (\%) & Provincial capital cities, $\mathrm{n}(\%)$ & Other, n (\%) & $\chi^{2}$ & $P$ \\
\hline Style of academic activities & & & & - & - \\
\hline Academic conference & $155(89.08)$ & $486(93.64)$ & $1,219(90.83)$ & & \\
\hline Online consultation & $44(25.29)$ & $119(22.93)$ & $236(17.59)$ & & \\
\hline Other & $1(0.57)$ & $3(0.58)$ & $7(0.52)$ & & \\
\hline Time interval & & & & - & - \\
\hline $8 \mathrm{am}-12 \mathrm{am}$ & $25(14.37)$ & $57(10.98)$ & $94(7.00)$ & & \\
\hline $2 \mathrm{pm}-6 \mathrm{pm}$ & $76(43.68)$ & $199(38.34)$ & $526(39.2)$ & & \\
\hline All time & $32(18.39)$ & $83(15.99)$ & $221(16.47)$ & & \\
\hline Date & & & & 38.7016 & $<0.0001$ \\
\hline Working days & $32(18.39)$ & $65(12.52)$ & $94(7.00)$ & & \\
\hline Saturdays and Sundays & $27(15.52)$ & $98(18.88)$ & $335(24.96)$ & & \\
\hline All time & $115(66.09)$ & $356(68.59)$ & $913(68.03)$ & & \\
\hline Weekly participation frequency & & & & 13.6228 & 0.0002 \\
\hline $1-3$ times & $110(63.22)$ & $380(73.22)$ & $1,028(76.6)$ & & \\
\hline More than 4 times & $64(36.78)$ & $139(26.78)$ & $314(23.40)$ & & \\
\hline More than 4 hours & $5(2.87)$ & $12(2.31)$ & $18(1.34)$ & & \\
\hline Academic activities sponsor & & & & - & - \\
\hline Unit/department & $75(43.1)$ & $220(42.39)$ & $532(39.64)$ & & \\
\hline Professional society/association & $137(78.74)$ & $416(80.15)$ & $1,081(80.55)$ & & \\
\hline Corporate organization & $83(47.7)$ & $267(51.45)$ & $666(49.63)$ & & \\
\hline Media & $44(25.29)$ & $102(19.65)$ & $305(22.73)$ & & \\
\hline Other & $9(5.17)$ & $37(7.13)$ & $106(7.9)$ & & \\
\hline
\end{tabular}

activities enables play back at a later stage. Third, good communication is not always achieved in traditional academic activities due to the physical spaces' variability and constraints. Moreover, the physical dimensions of the venue often restrict the number of audiences. While communication in online academic activities is no longer restricted geographically, each audience can ask questions to speakers, and even discuss with other audiences during the activities, which enhances the interaction between speakers and audiences. 
Table 6 Evaluation of the online academic activities between participants from different cities

\begin{tabular}{|c|c|c|c|c|c|}
\hline Items & First-tier cities, n (\%) & Provincial capital cities, $\mathrm{n}(\%)$ & Other, n (\%) & $\chi^{2}$ & $\mathrm{P}$ \\
\hline Energy consumption & & & & 6.4166 & 0.0404 \\
\hline Decrease & $128(69.19)$ & $401(75.09)$ & $1,087(77.59)$ & & \\
\hline No change & $36(19.46)$ & $96(17.98)$ & $213(15.2)$ & & \\
\hline Pressure & & & & 3.5927 & 0.1659 \\
\hline Decrease & $108(58.38)$ & $348(65.17)$ & $928(66.24)$ & & \\
\hline No change & 59 (31.89) & $143(26.78)$ & $370(26.41)$ & & \\
\hline Increase & $18(9.73)$ & $43(8.05)$ & $103(7.35)$ & & \\
\hline willing & $169(91.35)$ & $514(96.25)$ & $1,356(96.79)$ & & \\
\hline Screenshot of the activity contents & & & & 14.9929 & 0.0001 \\
\hline Unwilling & $12(6.49)$ & $36(6.74)$ & $39(2.78)$ & & \\
\hline willing & $173(93.51)$ & $498(93.26)$ & $1,362(97.22)$ & & \\
\hline Choice of online activities in the future & & & & 1.5777 & 0.2091 \\
\hline Unwilling & $0(0.00)$ & $2(0.37)$ & $9(0.64)$ & & \\
\hline willing & $185(100.00)$ & $532(99.63)$ & 1,392 (99.36) & & \\
\hline Future prevalence judgment & & & & 0.3499 & 0.5542 \\
\hline
\end{tabular}

Despite the many advantages of online academic activities, the study revealed that most participants considered that online academic activities have some shortcomings, including a lack of continuous communication with speakers after academic activities and the high demand for internet access. Post-conference interaction is important when participating in the academic activities, particularly for meeting potential collaborators and learning about new professional orientations to promote career development (9). Online academic activities only establish a video chat window, making it difficult to establish long-term and sustained communication opportunities. As a result, it is important to provide speakers and audiences with one-on-one discussions to promote exchanges and provide opportunities for collaborations. Additionally, extending communication time through the website, email, or phone after academic activities further promotes exchanges and collaborations opportunities. In response to the high internet demand for online academic activities, Gichora et al. recommended that recording speeches at least 2 weeks before the start of the activity, making them available to the conference team in the appropriate video format, and dealing with software compatibility issues promptly, can effectively prevent potential technical problems during online academic activities (4). Simultaneously, with the advent of the $5 \mathrm{G}$ era, constantly improving online academic software function can also effectively alleviate network congestion.

The subgroup analysis between speakers and audiences showed that online academic activities resulted in reduced stress. This could be due to the low cost, flexibility of time, and convenient participation in online academic activities, with some speakers attending more online academic activities. However, a considerable number of respondents 
Table 7 Differences between participants with different professional titles in the online academic activities

\begin{tabular}{|c|c|c|c|c|c|}
\hline Items & $\begin{array}{l}\text { Chief physician/associate } \\
\text { chief physician, n (\%) }\end{array}$ & $\begin{array}{c}\text { Attending physician, } \\
\mathrm{n}(\%)\end{array}$ & $\begin{array}{c}\text { Resident physician/ } \\
\text { student physician, n (\%) }\end{array}$ & $\chi^{2}$ & $P$ \\
\hline Total & 772 & 907 & 356 & & \\
\hline The Style of academic activities & & & & - & - \\
\hline Academic conference & $732(94.82)$ & $823(90.74)$ & $305(85.67)$ & & \\
\hline Other & $6(0.78)$ & $3(0.33)$ & $2(0.56)$ & & \\
\hline Time interval & & & & - & - \\
\hline 8 am-12 am & $58(7.51)$ & $74(8.16)$ & - & & \\
\hline All time & $110(14.25)$ & $166(18.3)$ & $60(16.85)$ & & \\
\hline Date & & & & 7.1714 & 0.0277 \\
\hline Working days & $50(6.48)$ & $84(9.26)$ & $57(16.01)$ & & \\
\hline Saturdays and Sundays & $183(23.7)$ & $198(21.83)$ & 79 (22.19) & & \\
\hline All time & $539(69.82)$ & $625(68.91)$ & $220(61.8)$ & & \\
\hline Weekly participation frequency & & & & 4.5553 & 0.0328 \\
\hline $1-3$ times & $564(73.06)$ & $667(73.54)$ & $287(80.62)$ & & \\
\hline More than 4 hours & $15(1.94)$ & $14(1.54)$ & $6(1.69)$ & & \\
\hline Academic activities sponsor & & & & - & - \\
\hline Unit/department & $253(32.77)$ & $401(44.21)$ & - & & \\
\hline Professional association & $656(84.97)$ & $720(79.38)$ & $258(72.47)$ & & \\
\hline Corporate organization & $417(54.02)$ & $460(50.72)$ & $139(39.04)$ & & \\
\hline Media & $140(18.13)$ & $222(24.48)$ & $89(25.00)$ & & \\
\hline Other & $49(6.35)$ & $62(6.84)$ & $41(11.52)$ & & \\
\hline
\end{tabular}

considered that their physical energy consumption in online academic activities significantly increased; speakers have to deliver more diversified and in-depth lectures, which increases energy consumption, especially for speakers in first-tier cities. Second, online activities based on network video software require the speakers to debug the network in advance and to pay attention to the internet connection, rather than the live audiences, resulting in increased psychological stress (6). The present study showed that many speakers were reluctant to accept the recording 
function of online video compared to audiences, especially for speakers in first-tier cities who indicated that they were more reluctant. One possible reason for this is that some academic findings are still in the research stage, and intellectual property issues, such as confidentiality or patents, should not be discussed publicly or published. Therefore, for speakers, especially those in first-tier cities, more attention should be paid to adjusting the level of stress and intellectual property protection to promote the quality of online academic activities.

Our survey study had some limitations. First, all respondents in this survey were oncologists from national medical centers in China. The results could represent the current situation of online academic activities for oncologists to some extent, but the sample size was still insufficient. Further studies should be conducted with larger sample sizes from more nationwide centers. Second, the COVID-19 pandemic created significant difficulties for research, and convenience sampling was considered a relatively efficient sampling method in the current context. However, convenience sampling may lead to selection bias. Multicenter randomized controlled studies are warranted to confirm the reliability of our results further.

With the continuous global spread of COVID-19, online academic activities will become the main form of academic exchanges among oncologists in the future (10). The present study's findings indicated that $99 \%$ of respondents would choose online academic activities in the future, and $90.6 \%$ thought online academic activities would become a popular trend in the future. Oncologists should take full advantage of online platforms to share the latest technologies in the fields. Improving online academic activity platforms and paying more attention to participants' requirements with different roles and title, and from different cities, are key to improving the quality of, and participation in, online academic activities.

\section{Acknowledgments}

Funding: This study was supported by Sanming Project of Medicine in Shenzhen (No. SZSM202011010) and the Non-profit Central Research Institution Fund of Chinese Academy of Medical Sciences (No. 2019PT310026).

\section{Footnote}

Reporting Checklist: The authors have completed the Quality assessment criteria for survey research reports Checklist.
Available at http://dx.doi.org/10.21037/atm-20-5051

Data Sharing Statement: Available at http://dx.doi. org/10.21037/atm-20-5051

Conflicts of Interest: All authors have completed the ICMJE uniform disclosure form (available at http://dx.doi. org/10.21037/atm-20-5051). The authors have no conflicts of interest to declare.

Ethical Statement: The authors are accountable for all aspects of the work in ensuring that questions related to the accuracy or integrity of any part of the work are appropriately investigated and resolved. The study was conducted in accordance with the Declaration of Helsinki (as revised in 2013). No other personal information was collected in the questionnaire. All participants in this survey have individual consent. The Research Ethics Committee of Cancer Hospital, Chinese Academy of Medical Sciences indicated that no ethics approval was required.

Open Access Statement: This is an Open Access article distributed in accordance with the Creative Commons Attribution-NonCommercial-NoDerivs 4.0 International License (CC BY-NC-ND 4.0), which permits the noncommercial replication and distribution of the article with the strict proviso that no changes or edits are made and the original work is properly cited (including links to both the formal publication through the relevant DOI and the license). See: https://creativecommons.org/licenses/by-nc-nd/4.0/.

\section{References}

1. Gates B. Responding to Covid-19 - A Once-in-a-Century Pandemic? N Engl J Med 2020;382:1677-9.

2. World Health Organization. Coronavirus Disease 19 (COVID-19) Situation. Available online: https://www. who.int/emergencies/diseases/novel-coronavirus-2019/ situation-reports/

3. Chen S, Yang J, Yang W, et al. COVID-19 control in China during mass population movements at New Year. Lancet 2020;395:764-6.

4. Gichora NN, Fatumo SA, Ngara MV, et al. Ten simple rules for organizing a virtual conference--anywhere. PLoS Comput Biol 2010;26;6:e1000650.

5. Viglione G. A year without conferences? How the coronavirus pandemic could change research. Nature 2020;579:327-8. 
6. Woolston C. Learning to love virtual conferences in the coronavirus era. Nature 2020;582:135-6.

7. Cailianshe. China Anti-Cancer Association teamed up with "Good Medical Association": A large-scale online cancer science answering activity officially launched. Available online: http://hebei.ifeng.com/a/20200414/14108217_0. shtml

8. Sina. Experts from various countries meet in the cloud

Cite this article as: Gao F, Wei L, Chen Q, Shang W, Yang Z, Wen Y, Yan S, Hu H, Zhang R, Li N, Zhao H. Current situation and trends of online academic activities for oncologists during the COVID-19 pandemic: a multicenter survey. Ann Transl Med 2020;8(23):1559. doi: 10.21037/atm-20-5051 to exchange the war epidemic. Available online: https:// tech.sina.com.cn/roll/2020-04-02/doc-iimxyqwa4603133. shtml? cre=tianyi \&mod=pcpager_news $\&$ loc $=38 \& \mathrm{r}=9 \& \mathrm{rfun}$ $\mathrm{c}=30 \& \mathrm{tj}=$ none \& $\mathrm{tr}=9$

9. Achakulvisut T, Ruangrong T, Bilgin I, et al. Improving on legacy conferences by moving online. Elife 2020;9:e57892.

10. Sun L, Tang Y, Zuo W. Coronavirus pushes education online. Nat Mater 2020;19:687. 


\section{Supplementary}

Table S1 The association between influence factors and the change in the proportion of the online academic activities during the pandemic

\begin{tabular}{|c|c|}
\hline Items & OR $(95 \% \mathrm{Cl})^{\star}$ \\
\hline First-tier cities & $1.089(0.778-1.524)$ \\
\hline Provincial capital cities & $0.932(0.749-1.158)$ \\
\hline Other & Reference \\
\hline Special oncology hospitals & $1.351(0.971-1.88)$ \\
\hline Grade III level A hospitals & $1.474(1.202-1.808)$ \\
\hline Other hospitals & Reference \\
\hline \multicolumn{2}{|l|}{ Department } \\
\hline Radiation oncology & $1.252(0.823-1.904)$ \\
\hline Other & Reference \\
\hline \multicolumn{2}{|l|}{ Job title } \\
\hline Chief physician/associate chief physician & $1.358(1.032-1.788)$ \\
\hline Attending physician & $1.095(0.85-1.409)$ \\
\hline Resident physician/student physician & Reference \\
\hline \multicolumn{2}{|l|}{ Status } \\
\hline Speakers/chairmen & $1.759(1.382-2.239)$ \\
\hline
\end{tabular}

*, positive outcome was defined as an increase of more than $40 \%$ in the proportion of online academic activity during the pandemic of COVID-19. 